\title{
Influência Majoritária em Eleições Proporcionais: Os Efeitos Presidenciais e Governatoriais sobre as Eleições para a Câmara dos Deputados Brasileira (1994-2010**
}

\author{
Márcia Miranda Soares
}

Professora-adjunta do Departamento de Ciência Política da Universidade Federal de Minas Gerais (UFMG).E-mail: marciamsoares@uol.com.br

\section{INTRODUÇão}

$\mathrm{O}$ sistema eleitoral brasileiro combina o modelo majoritário para os cargos executivos dos três níveis da Federação, presidente, governadores de estado e prefeitos, com o modelo proporcional para os legislativos nacional e subnacionais, deputado federal, deputado estadual e vereadores. No nível nacional, o Poder Legislativo é bicameral. Para as eleições dos 81 membros do Senado o sistema é majoritário, sendo que a cada quatro anos há renovação parcial desta Casa, ora de um terço dos seus membros, ora de dois terços dos mesmos.

No contexto atual da democracia brasileira, algumas mudanças ocorreram no processo eleitoral. Em 1989, por ocasião da primeira eleição direta para presidente, as eleições para Presidência ocorreram solteiras, sem qualquer eleição para o Legislativo nacional. Em 1990, foram

\footnotetext{
* Agradeço ao Instituto de Estudos Sociais e Políticos (IESP) da Universidade do Estado do Rio de Janeiro (UERJ) e ao Conselho Nacional de Desenvolvimento Científico e Tecnológico (CNPq), que propiciaram a realização da pesquisa de doutorado que originou a primeira versão deste artigo. Ao professor Fabiano Santos, meu orientador, agradeço os comentários que possibilitaram aperfeiçoar o trabalho. Aos pareceristas anônimos da revista Dados, agradeço a acuidade na leitura e as críticas valiosas que possibilitaram melhorias no texto final. Por fim, agradeço aos meus bolsistas de iniciação científica, Bruno Guimarães e Camylla Cotta, que trabalharam na composição e análises do banco de dados.
}

DADOS - Revista de Ciências Sociais, Rio de Janeiro, vol. 56, no-2, 2013, pp. 413 a 437. 
realizadas eleições para governadores, deputados estaduais, deputados federais e um terço dos senadores.

A forma como se configura o calendário eleitoral em um regime democrático tem pretensões e consequências políticas, evidentemente. Nos Estados Unidos, por exemplo, as eleições do Legislativo no meio do mandato presidencial funcionam como importante indicador de popularidade e satisfação dos cidadãos com o Poder Executivo nacional. No Brasil, eleições legislativas nacionais casadas com eleições estaduais e descoladas das eleições presidenciais foram apontadas como fator de enfraquecimento do poder presidencial e fortalecimento dos governadores de Estado na esfera política nacional.

Juan Linz (1990) defendeu que eleições distintas e independentes para o Executivo e o Legislativo nacional resultavam na ausência de vínculos eleitorais e, por sua vez, em baixa coordenação entre os poderes, causando ingovernabilidade e instabilidade política. Abrucio (1998) e Samuels (2003) destacaram, como efeito deste calendário, o aumento da influência dos governadores sobre as eleições legislativas nacionais e, consequentemente, o poder destes atores na política nacional.

A partir de 1994, este quadro eleitoral foi alterado, passando as eleições presidenciais a coincidirem com as eleições para deputados federais, senadores, governadores e deputados estaduais, só permanecendo descoladas as eleições para prefeitos e vereadores. Em 1998, houve outra mudança importante, com a introdução da reeleição para cargos do Poder Executivo, o que possibilitou a presidentes, governadores e prefeitos a recondução aos cargos, por um único período subsequente.

Contudo, mesmo após as mudanças, a tese do poder dos governadores no âmbito eleitoral não foi abandonada, dado que o calendário eleitoral seria tão somente um dos fatores da dinâmica eleitoral a responder por este poder e as eleições estaduais e nacionais continuaram coincidentes.

Abrucio (1998) indicou que o poder dos governadores diminuiu, porque as eleições do presidente e do Legislativo nacional passaram a ser casadas, devido ao instituto da reeleição e por mudanças conjunturais ocorridas no governo do presidente Fernando Henrique Cardoso (1995-2002). Samuels (2003) continuou a defender a posição privilegiada dos governadores na arena eleitoral e na política nacional, alegando que estes continuaram a dominar o processo eleitoral para a câmara 
baixa nos distritos eleitorais, que correspondem aos estados da Federação. O que estes autores estabeleceram para o caso brasileiro foi uma conexão eleitoral federativa, na qual governadores seriam atores estratégicos nas eleições para a Câmara dos Deputados e, com isto, obteriam o apoio dos parlamentares aos seus interesses nas votações de matérias legislativas. Esta perspectiva, que tem outros adeptos, destacando os chamados brasilianistas, estrangeiros que estudam a política brasileira, privilegia as variáveis dos sistemas partidário e eleitoral como determinantes do comportamento legislativo na Câmara dos Deputados brasileira (Mainwaring, 2001; Garman, Haggard e Willis, 2001; Ames, 2003).

Os autores também imputaram consequências negativas do poder dos governadores para a política e a economia brasileiras. Os governadores seriam atores de veto, atuando via Legislativo nacional, às ações do Poder Executivo central, gerando instabilidade política e ameaça de paralisia decisória à jovem democracia brasileira. O bloqueio dos governadores atingiria, principalmente, as iniciativas de reformas modernizantes voltadas para o desenvolvimento político e econômico do país, como o fim da guerra fiscal entre os estados, a reforma tributária, o saneamento fiscal das contas públicas, entre outras medidas (Samuels e Mainwaring, 2004).

Há duas dimensões na tese do poder dos governadores que precisam ser demarcadas e analisadas para uma melhor compreensão da política brasileira. Uma diz respeito à dinâmica eleitoral, na qual existe a hipótese de influência dos governadores de Estado sobre as eleições para o Legislativo nacional. A outra dimensão diz respeito às consequências da dinâmica eleitoral para o comportamento parlamentar, com destaque para a relação Executivo e Legislativo. Sobre esta última dimensão, a hipótese do poder dos governadores na política nacional é questionada por uma ampla literatura que aponta a insuficiência da dinâmica eleitoral para explicar o comportamento parlamentar e apresenta outras variáveis importantes a serem consideradas: as regras internas de funcionamento do Legislativo (Cox e McCubbins, 1993) e os mecanismos de que dispõe o Poder Executivo nacional para influenciar os congressistas (Shugart e Carey, 1992). Para o caso brasileiro, tais variáveis têm sido destacadas nas obras de Figueiredo e Limongi (2001), Cheibub, Figueiredo e Limongi (2003), Santos (1997 e 1999), Amorim Neto (2000), Amorim Neto e Santos (2001 e 2003). Os resultados destes trabalhos mostram que o comportamento parlamentar brasileiro, no 
atual período democrático, tem sido marcado por disciplina partidária e sucesso do Executivo nacional na aprovação de sua agenda governamental, algo explicado pela centralização das tomadas de decisão na Câmara dos Deputados nas lideranças partidárias e pelos recursos de que dispõe o Executivo para legislar e obter apoio parlamentar às suas iniciativas de lei. Entre estes recursos, destacam-se a distribuição de cargos governamentais para constituição de uma base partidária aliada ao governo no Legislativo nacional (coalizão de governo) e o controle dos recursos orçamentários.

No presente artigo, a atenção recai sobre a dinâmica eleitoral brasileira, mais especificamente sobre a influência que os cargos majoritários podem exercer nas eleições para deputado federal. O propósito de tal investigação é verificar se um partido tem sua performance eleitoral para a câmara baixa influenciada pela ocupação de cargos de governador e/ou presidente e/ou pela apresentação e pelo desempenho de candidatos aos cargos majoritários para os executivos estaduais e federal. A análise é importante não somente para dialogar com a literatura que defende o poder dos governadores de Estado nas eleições legislativas, como para ajudar a entender a dinâmica eleitoral brasileira. Em que medida a ocupação de cargos executivos no plano nacional e subnacional impactam as eleições legislativas? Os governadores têm impacto decisivo nas eleições para a câmara baixa brasileira, são as “locomotivas" das eleições legislativas, como defendem Abrucio (1998) e Samuels (2003)? As eleições majoritárias, presidenciais ou governatoriais, com maior visibilidade e recursos, influenciam as eleições para deputado federal? Candidatos fortes nas disputas majoritárias impulsionam seus partidos na votação para a câmara baixa? E quem impacta mais as eleições legislativas: presidentes ou governadores, candidatos à presidência ou aos governos estaduais?

Para responder a essas questões, o artigo está organizado em quatro seções. A primeira apresenta o debate sobre a influência majoritária em eleições proporcionais, destacando como eleições majoritárias podem impactar eleições proporcionais (efeitos coattails) ${ }^{1}$ e o possível efeito que a ocupação de cargos majoritários pode ter sobre as eleições para deputado federal.

A seção seguinte apresenta a proposta metodológica para a análise da influência majoritária nas eleições para a câmara baixa brasileira. A inspiração geral vem de Samuels (2003), que resgatou a literatura de coattails eleitorais dos Estados Unidos para verificar e comparar, no caso brasileiro, a capacidade de candidatos a presidente e a governa- 
dor de arrastar seus partidos nas eleições legislativas para a câmara baixa, os coattails presidenciais e os coattails governatoriais. Por meio de dados eleitorais e modelos analíticos distintos do autor, utiliza-se a análise de regressão para verificar os impactos de algumas variáveis sobre a votação recebida pelos partidos para deputado federal, nos estados (distritos), nas cinco últimas eleições. Destacam-se entre as variáveis explicativas o fato de o partido ocupar ou não a Presidência e/ ou governos estaduais e a votação recebida para os cargos majoritários de presidente e governador.

A terceira seção apresenta e analisa os resultados obtidos a partir dos métodos utilizados. Os achados não apontam correlação com significância estatística entre o partido estar à frente da Presidência e/ou de governos estaduais e a votação recebida pelo partido para deputado federal. Por outro lado, verifica-se que as eleições para presidente e governador têm efeito sobre a votação dos partidos para câmara baixa, candidatos a presidente ou governadores bem votados potencializam a votação do seu partido para deputado federal, sendo que este efeito é maior para governadores (coattails governatoriais) que para presidentes (coattails presidenciais). Contudo, a principal variável a explicar a votação de um partido para deputado federal é a votação deste mesmo partido na eleição imediatamente anterior, indicando que os partidos detêm um capital eleitoral nos estados, nas eleições para câmara baixa, que independe das disputadas majoritárias.

Por fim, a quarta e última seção é dedicada a algumas considerações finais, na qual se destaca a importância do federalismo para entender a composição do Legislativo nacional. Também aponta a necessidade de mais pesquisas para entender a relação entre dinâmica eleitoral e dinâmica parlamentar, com destaque para a relação Executivo e Legislativo, mesmo admitindo que tal relação não signifique ingovernabilidade e paralisia decisória na jovem democracia brasileira.

\section{INFLUÊNCIA MAJORITÁRIA EM ELEIÇÕES PARLAMENTARES}

\section{A Influência das Eleições Majoritárias sobre as Eleições Parlamentares: Efeitos Coattails}

O termo coattail eleitoral foi cunhado pela ciência política norte-americana para designar a influência que as eleições para cargos executivos exercem sobre as eleições para cargos legislativos. Nas eleições presidenciais dos Estados Unidos, os candidatos contam com recursos financeiros milionários para suas campanhas, participam de disputa 
política nacional acirrada entre os dois partidos dominantes, Republicano e Democrata, são destaques nos meios de comunicação e têm maior visibilidade política junto ao eleitorado, o que os torna cabos eleitorais privilegiados de seus partidos na disputa aos postos legislativos. Assim, a literatura destaca que candidatos populares à Presidência, com forte votação, são capazes de puxar votos para suas legendas na competição para os cargos do Legislativo nacional: efeitos coattails presidenciais.

Os estudos sobre efeitos coattails no Legislativo norte-americano têm se concentrado em expor como as eleições presidenciais influenciam as votações ou a obtenção de cadeiras dos partidos Democrata ou Republicano para a Câmara dos Deputados ou para o Senado. A polêmica entre os estudiosos gira em torno da evolução dos efeitos coattails presidenciais ao longo do tempo, com a maioria defendendo o declínio desses efeitos a partir dos anos 1950 (Ferejohn e Calvert, 1984), e outros sustentando a persistência dos efeitos coattails presidenciais (Born, 1984).

O principal interesse pelos efeitos que as eleições presidenciais produzem sobre as eleições parlamentares nos Estados Unidos não estaria propriamente na arena eleitoral, mas no momento pós-eleitoral, quando o presidente buscará apoio do Congresso para aprovar as medidas políticas de seu interesse. Os efeitos coattails presidenciais, para a maioria dos seus estudiosos, é um fator importante para definir a relação Executivo e Legislativo. Candidatos presidenciais fortes eleitoralmente podem angariar votos para seus partidários e obter uma base de apoio majoritária e duradoura no Legislativo nacional. Ferejohn e Calvert (1984) sustentam que os presidentes necessitam de algum mecanismo para obter apoio dos congressistas às suas políticas e que tal mecanismo deve ser buscado na arena eleitoral, mais especificamente na capacidade do presidente de puxar votos para os candidatos de seu partido nas eleições legislativas. Em síntese, os efeitos coattails presidenciais são apresentados como uma variável a ser incorporada à teoria das conexões eleitorais que buscam explicar o comportamento parlamentar. Contudo, em termos de evidências empíricas, estes estudos têm se concentrado em medir os efeitos dos coattails presidenciais, não havendo a preocupação em relacionar tais efeitos com os resultados da produção legislativa.

A análise de efeitos coattails é pertinente para o Brasil, país presidencialista marcado por dois processos eleitorais distintos de escolha dos 
ocupantes dos cargos executivos e legislativos, princípio majoritário na escolha de presidentes, governadores e prefeitos e princípio proporcional adotado na definição dos ocupantes dos postos legislativos nacionais e subnacionais. Como nos Estados Unidos, as eleições brasileiras para os cargos majoritários mobilizam maiores recursos e prevalecem em termos de projeção e interesse por parte do eleitorado sobre as eleições legislativas, o que nos leva à conclusão de que as eleições majoritárias podem ter efeitos coattails sobre as eleições parlamentares. Contudo, a análise de efeitos coattails no caso brasileiro requer adaptar a teoria e os métodos adotados para os Estados Unidos a uma realidade bastante distinta. Em vez de um sistema bipartidário, no qual se verifica a relação entre os votos presidenciais e os votos parlamentares dos dois partidos majoritários, cabe analisar os efeitos coattails em uma realidade multipartidária, na qual vários candidatos aos cargos majoritários podem influenciar seus respectivos partidos ou coligações partidárias na corrida aos cargos legislativos. Ao invés de restringir os efeitos das eleições majoritárias à corrida presidencial, cabe também verificar os efeitos das eleições governatoriais sobre o Legislativo nacional, dadas as peculiaridades do sistema eleitoral brasileiro, entre elas: eleições casadas para os cargos de presidente, governador e deputado federal; recursos de campanhas concentrados no nível estadual e estados como distritos eleitorais dos parlamentares nacionais.

Samuels (2003) adotou a análise de coattails para mostrar que os candidatos a governadores predominam sobre os candidatos presidenciais no processo de escolha dos deputados federais brasileiros. Assim, diferente da análise dos efeitos coattails nos Estados Unidos, o autor concentrou-se em comparar os efeitos coattails presidenciais e os efeitos coattails governatoriais nas eleições legislativas nacionais. A perspectiva das conexões eleitorais e do impacto dos coattails sobre o comportamento parlamentar se manteve na análise de Samuels para o Brasil. O autor defendeu que a prevalência dos efeitos coattails governatoriais resulta em um foco distinto de fidelidade e apoio no Legislativo nacional. Em vez do foco ser o presidente, os deputados têm como referência os governadores de Estado e são influenciados por estes em suas votações de matérias legislativas².

Neste artigo, o pressuposto é que o comportamento parlamentar, com destaque para a relação Executivo e Legislativo, não pode ser derivado diretamente do comportamento dos atores na arena eleitoral, desconsiderando outras variáveis da dinâmica política nacional. Assim, esta 
não é a principal motivação na análise de coattails, sua relevância reside no que ela elucida da própria dinâmica eleitoral. Neste aspecto, permite verificar correlações nas votações para os cargos de presidente, governadores de estado e deputados federais. Com isto, podemos observar o atrelamento destas disputas e indagar sobre as estratégias partidárias para conquistar cargos no Legislativo nacional.

\section{A Influência da Ocupação de Cargos Majoritários sobre as Eleições Parlamentares}

Para além dos efeitos coattails eleitorais, é pertinente verificar a influência que a ocupação dos cargos de presidente e/ou de governador de estado pode ter sobre as eleições legislativas nacionais na câmara baixa. Com isto, busca-se discernir melhor os termos do debate e evitar certa confusão presente nos atores que defendem a tese do poder dos governadores no plano nacional sem distinguir claramente ocupantes e postulantes aos cargos de presidente e governador.

Estar à frente da Presidência da República ou de governos estaduais pode contribuir para a conquista de votos para a Câmara dos Deputados. Conforme Abrucio (1998), os governadores podem otimizar a performance eleitoral de seus partidos ou coligados para deputado federal porque contam com recursos importantes para serem utilizados nas bases eleitorais destes: cargos, verbas para obras, apoio de deputados estaduais e prefeitos, que funcionam como cabos eleitorais, entre outros. De forma similar, podemos estender estes mesmos recursos ao governo federal. Pereira e Mueller (2002) destacam, para o contexto nacional, o controle do Executivo federal na liberação de recursos financeiros destinados a atender as emendas parlamentares no orçamento da União. As emendas, geralmente, estão voltadas para o atendimento das bases eleitorais dos deputados federais e podem contribuir para o seu futuro sucesso eleitoral, seja na reeleição ou na conquista de novos cargos políticos.

Contudo, a despeito dos recursos, presidentes e governadores podem ser impopulares e não conseguirem eleger seus sucessores ou mesmo não se reelegerem. Isto significa também baixa capacidade de arrastar votos para sua legenda. Pereira e Rennó (2007), ao analisarem os fatores que geraram sucesso eleitoral para os deputados federais que buscavam a reeleição, em 1998 e 2002, observaram impactos distintos da vinculação dos deputados federais com o presidente nos dois períodos. Em 1998, diante de um presidente que buscava a reeleição e goza- 
va de alta popularidade, a aproximação com o presidente (pertencer a sua coalizão de governo e ter maior execução financeira de emendas orçamentárias individuais) se mostrou relevante para o sucesso na busca da reeleição. Em 2002, com um cenário diferente, no qual o presidente não era candidato à reeleição e sofreu expressiva queda na sua popularidade, o que se fez acompanhar de crescimento da oposição na corrida presidencial, a aproximação com o Executivo federal não gerou impactos no sucesso eleitoral.

Desta forma, além de distinguir a influência que pode ter a ocupação ou postulação de um cargo majoritário sobre as eleições para Câmara dos Deputados, parece relevante identificar se os partidos que concorrem aos cargos legislativos têm um presidente e/ou governadores de estados que são incumbentes, ou seja, candidatos à reeleição. A combinação das duas condições, ocupante e postulante, pode significar força adicional no arraste da votação legislativa, ou não, a situação de postulante pode estar associada a baixo poder sucessório derivado de desgaste governamental.

\section{MEDINDO INFLUÊNCIA MAJORITÁRIA NAS ELEIÇÕES PARA A CÂMARA DOS DEPUTADOS BRASILEIRA}

Para avaliar os efeitos majoritários sobre as eleições proporcionais, foi utilizada a análise de regressão estatística. A escala de mensuração das principais variáveis e a quantidade de variáveis independentes, assim como a associação observada entre estas e a variável dependente, levou à adoção do modelo de regressão linear multivariada.

\section{Variáveis e Hipóteses}

A variável dependente consiste na votação recebida pelo partido político para o cargo de deputado federal, nos estados brasileiros, em cada uma das últimas cinco eleições. A métrica utilizada é o percentual de votos recebido pelo partido no estado em relação ao total de votos válidos distribuídos entre os diversos partidos no mesmo estado (Votação Partidária para Deputado Federal). Espera-se que esta variável seja impactada pelo seguinte conjunto de variáveis independentes e com as seguintes direções:

\section{Ocupação de Cargos Majoritários Nacionais e Estaduais}

A ocupação de cargos majoritários (Presidência; Governo Estadual) pode significar o acesso a importantes recursos de governo (cargos, 
verbas públicas e execução de políticas públicas) e impactar positivamente a votação dos partidos nas eleições para deputado federal nos estados. Tal efeito pode ser potencializado se o partido ocupar simultaneamente os dois postos (Presidência e Governo estadual). Para estas três variáveis independentes foram utilizadas variáveis dicotômicas para verificar se o partido ocupa a Presidência, se ocupa o Governo estadual ou se ocupa simultaneamente os dois cargos, atribuindo valor um para cada uma destas condições, e zero, em caso negativo.

\section{Efeitos Coattails Presidenciais e Governatoriais}

As eleições majoritárias, por concentrarem recursos e visibilidade, podem influenciar as eleições proporcionais da câmara baixa brasileira. Assim, os partidos políticos fortes na disputa pela Presidência ou pelos governos dos estados podem arrastar os votos de suas legendas partidárias para a Câmara dos Deputados (Votação Presidente; Votação Governador).

Pode-se considerar, ainda, que partidos sem candidatos próprios à Presidência ou ao Governo estadual podem se beneficiar de fazer parte de uma coligação eleitoral forte para os cargos majoritários, capaz de puxar votos para as legendas coligadas na disputa legislativa. Evidentemente, a votação de um partido que tem candidato próprio à Presidência é a mesma votação da coligação presidencial para os partidos que não tiveram candidatos próprios e se coligaram àquele. Serão utilizados dois modelos para distinguir os partidos que tiveram candidatos próprios aos cargos majoritários e aqueles que se coligaram a candidatos de outros partidos (Votação Coligação Presidente; Votação Coligação Governador).

É também razoável supor que presidentes ou governadores incumbentes têm uma força diferenciada nas eleições, visto que concentram recursos de governo e de campanha, podendo impulsionar ainda mais a votação de seus partidos para deputado federal. Para esta análise adotaram-se duas medidas, um primeiro modelo, com variáveis dicotômicas, para verificar se o partido tem um presidente ou um governador que concorre à reeleição (Presidente Incumbente; Governador Incumbente), atribuindo valor um para estas condições, e zero, em caso contrário. Um segundo modelo incluiu como variáveis independentes a votação obtida pelos candidatos incumbentes (Votação Presidente Incumbente; Votação Governador Incumbente). 
Por fim, outra variável independente do modelo é a votação recebida pelo partido para deputado federal na eleição imediatamente anterior (Votação Anterior). Com ela, buscaremos verificar se existe um padrão de votação legislativa nos partidos políticos que independe dos cargos majoritários, ou seja, um partido político pode ter um "capital eleitoral" em um estado que independe dos ocupantes ou postulantes aos cargos de governador e presidente.

Para as variáveis Votação Presidente; Votação Coligação Presidente; Votação Governador, Votação Coligação Governador e Votação Anterior foi considerado o percentual da votação recebida pelo partido ou coligação, no estado, no primeiro turno das disputas majoritárias, exatamente quando ocorreram as eleições proporcionais.

A partir destas variáveis, as hipóteses de trabalho sustentam que a votação do partido político para o cargo de deputado federal aumenta se:

$\mathrm{H}_{1}$ : o partido ocupa o cargo de presidente da República (Presidência);

$\mathrm{H}_{2}$ : aumenta a votação do partido para o cargo de presidente (Votação Presidente);

$\mathrm{H}_{3}$ : aumenta a votação da coligação partidária para o cargo de presidente (Votação Coligação Presidente);

$\mathrm{H}_{4}$ : o partido tem um presidente que concorre à reeleição (Presidente Incumbente);

$\mathrm{H}_{5:}$ aumenta a votação do presidente incumbente (Votação Presidente Incumbente);

$\mathrm{H}_{6}$ : o partido ocupa o cargo de governador de estado (Governo Estadual);

$\mathrm{H}_{7}$ : aumenta a votação do partido para o cargo de governador (Votação Governador);

$\mathrm{H}_{8}$ : aumenta a votação da coligação partidária para o cargo de governador (Votação Coligação Governador);

$\mathrm{H}_{9}$ : o partido tem um governador que concorre à reeleição (Governador Incumbente);

$\mathrm{H}_{10 \text { : }}$ aumenta a votação do governador incumbente (Votação Governador Incumbente);

$\mathrm{H}_{11}$ : o partido ocupa simultaneamente o cargo de presidente da República e de governador do estado (Presidência e Governo Estadual); 
$\mathrm{H}_{12}$ : aumenta a votação recebida para deputado federal em eleição anterior (Votação Anterior).

\section{Modelos Analíticos}

Para testar essas hipóteses, foram definidos três modelos de regressão. Os dois primeiros, e principais modelos, trabalham com os partidos que tiveram candidatos próprios à Presidência ou aos governos estaduais. Isto nos permite correlacionar a votação para deputado federal com as votações recebidas pelos partidos para os cargos executivos nacional e estaduais. O modelo dois difere do primeiro porque inclui, além das variáveis dicotômicas referentes à presidente/governador incumbente igual a 1 (um) e desafiador igual a 0 (zero), a interação destas com as respectivas votações dos incumbentes ${ }^{3}$. Busca-se, desta forma, analisar com maior precisão o efeito que o presidente ou governador incumbente pode ter sobre a votação dos partidos para deputado federal.

Os modelos 1 e 2 podem ser expressos pelas equações:

Votação Partidária Deputado Federal ${ }_{\mathrm{st}}=\mathrm{B} 0+\mathrm{B} 1 *$ Presidência $_{\mathrm{t}}+\mathrm{B} 2^{*} \mathrm{Vo}_{\mathrm{o}}$ tação Presidente $_{s t}+B 3^{*}$ Presidente Incumbente ${ }_{t}+B 4^{*}$ Governo Estadual $_{\mathrm{st}}+\mathrm{B} 5^{*}$ Votação Governador $_{\mathrm{st}}+\mathrm{B}^{*}{ }^{*}$ Governador Incumbente st $_{\mathrm{s}}+$

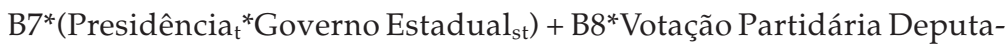
do Federal $\mathrm{s}_{\mathrm{s}(\mathrm{t}-1)}+$ Erro

Votação Partidária Deputado Federal $\mathrm{st}_{\mathrm{st}}=\mathrm{B} 0+\mathrm{B} 1 *$ Presidência $_{\mathrm{t}}+\mathrm{B} 2^{*}$ Votação Presidente $_{s t}+B 3^{*}$ Presidente Incumbente ${ }_{t}+B 4^{*} V_{\text {Votação Presiden- }}$ te Incumbente ${ }_{t}+B 5^{*}$ Governo Estadual $_{\text {st }}+B 6^{*}$ Votação Governador $_{\text {st }}+$ $B 7^{*}$ Governador Incumbente ${ }_{s t}+B 8^{*}$ Votação Governador Incumbente ${ }_{s t}$ + B9*(Presidência ${ }^{*}$ Governo Estadual $\left.{ }_{s t}\right)+$ B10*Votação Partidária Deputado Federal $_{s(t-1)}+$ Erro

Em que:

t = Ano da eleição (1994, 1998, 2002, 2006 ou 2010)

$\mathrm{s}=$ Estados (Acre, Amapá, Amazonas, Alagoas...)

No modelo três, considera-se os partidos que não tiveram candidatos majoritários próprios, mas que participaram de coligações eleitorais para presidente ou governador. Assim, em vez da votação destes partidos para presidente ou governador de estado, tem-se a votação da coligação para estes cargos: 
Votação Partidária Deputado Federal $\mathrm{st}_{\mathrm{t}}=\mathrm{B} 0+\mathrm{B} 1 *$ Presidência $_{\mathrm{t}}+\mathrm{B} 2 * \mathrm{Vo}_{\mathrm{o}}$ tação Coligação Presidente ${ }_{s t}+B{ }^{*}$ Presidente Incumbente $_{t}+B 4^{*}$ Governo Estadual st + B5*Votação Coligação Governador ${ }_{\mathrm{st}}+\mathrm{B} 6^{*}$ Governador Incumbente $_{\text {st }}+B 7^{*}\left(\right.$ Presidência $_{t}{ }^{*}$ Governo Estadual $\left.{ }_{\text {st }}\right)+B 8^{*}$ Votação Partidária Deputado Federal $\mathrm{s}(\mathrm{t}-1)+$ Erro

\section{Período, Amostra e Dados}

O período selecionado corresponde às cinco últimas eleições para a Câmara dos Deputados (1994, 1998, 2002, 2006 e 2010) e contempla o universo de eleições casadas para presidente, governador de estado e deputado federal no regime democrático atual. Tal restrição possibilita uma avaliação mais criteriosa dos efeitos coattails presidenciais e governatoriais, sem qualquer defasagem de tempo entre estes processos eleitorais, algo que necessitou ser ponderado em outros estudos que abordaram períodos anteriores, como o de Samuels (2003).

A unidade de análise é o partido político, em cada estado, com restrição da amostra aos dez maiores partidos com representação política na Câmara dos Deputados no período. Estes partidos conquistaram 92\% da representação parlamentar, conforme Tabela 1, e nos permitem uma análise estatística mais apurada dos efeitos majoritários, visto que eles representam também os principais partidos que ocuparam e pleitearam os cargos majoritários. Ainda, a restrição possibilita avaliar os efeitos majoritários efetivos sobre a composição da Câmara dos Deputados, ou seja, em que medida presidente ou governador, candidatos a presidente ou a governador contribuíram para a obtenção de cadeiras na Câmara dos Deputados. Estatisticamente, a restrição possibilita trabalhar com uma correlação mais linear entre as variáveis e com menos omissões nos dados (missings).

O banco de dados foi construído, predominantemente, com informações eleitorais disponibilizadas pelo Tribunal Superior Eleitoral (TSE, 2011), em seu sítio eletrônico, e por Nicolau (2006). 


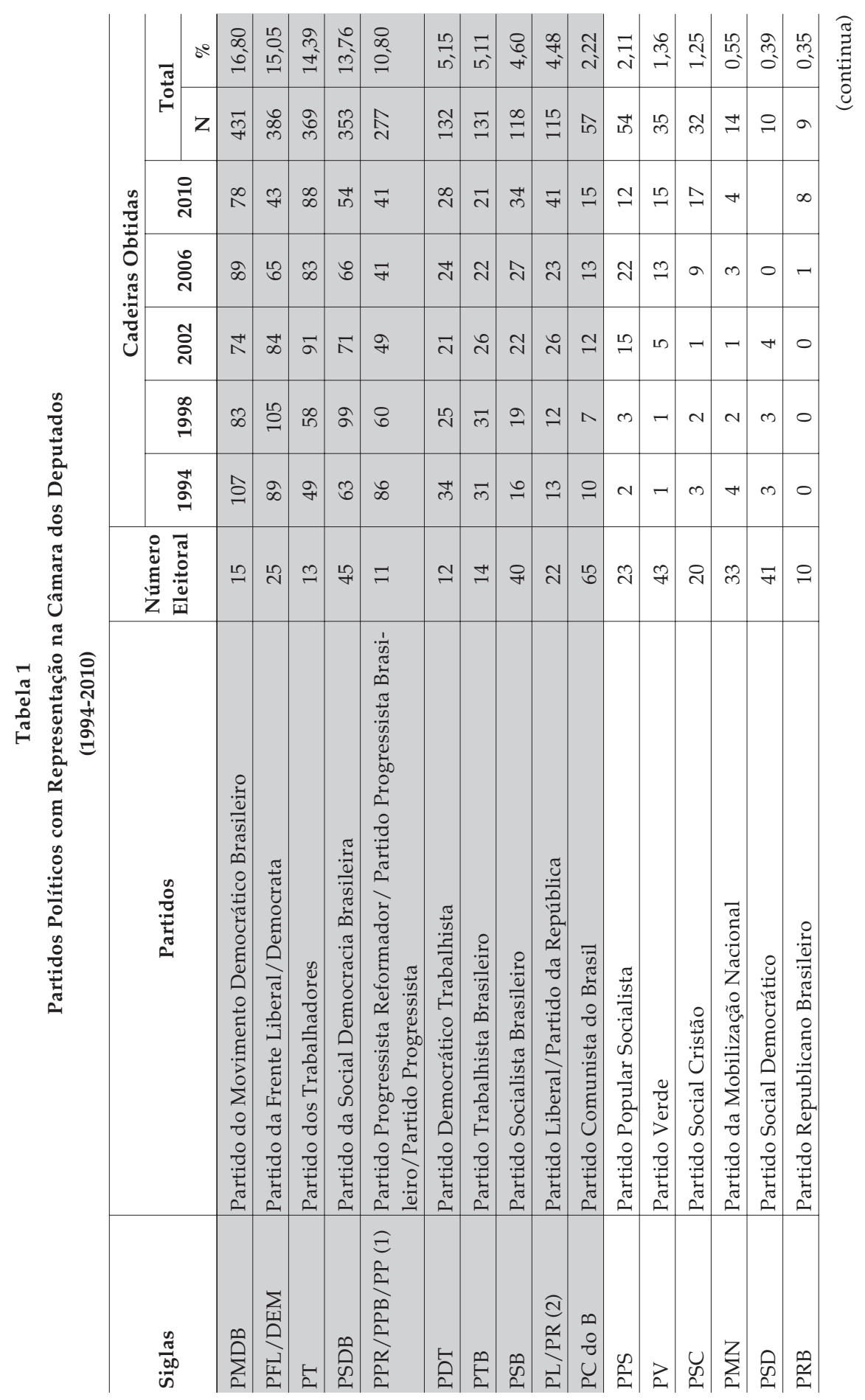




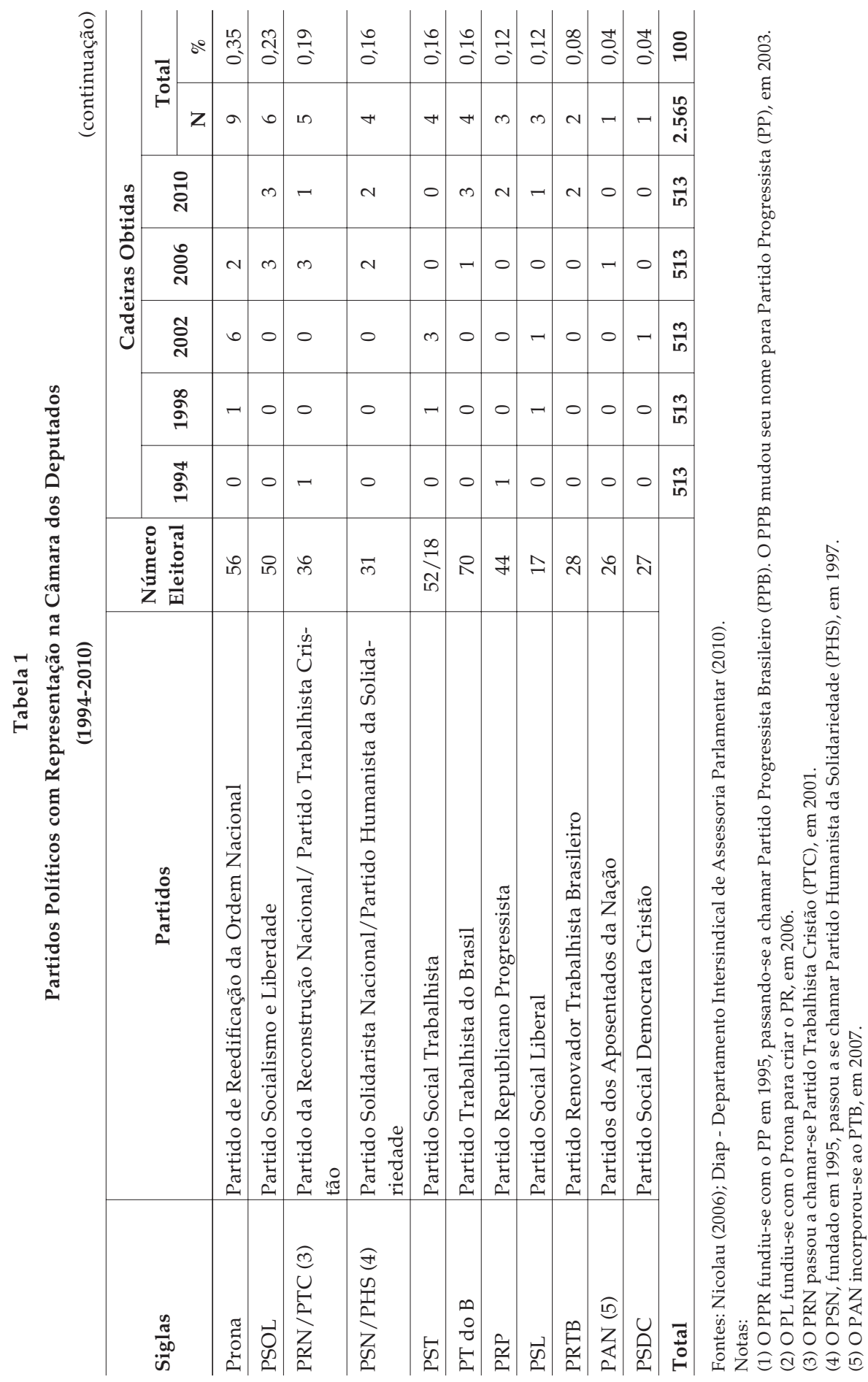

DADOS - Revista de Ciências Sociais, Rio de Janeiro, vol. 56, nำ 2, 2013 


\section{RESULTADOS}

A Tabela 2 apresenta os resultados obtidos para os três modelos adotados. O modelo 1 apresenta 219 observações e explica 65\% $\left(R^{2}\right)$ da votação recebida para deputado federal. Neste modelo, os resultados en-

Tabela 2

Efeitos Majoritários nas Eleições para a Câmara dos Deputados Brasileira (1994-2010)

Variável Dependente: Votação Partidária para Deputado Federal

\begin{tabular}{|c|c|c|c|}
\hline & Modelo 1 & Modelo 2 & Modelo 3 \\
\hline Constante & $\begin{array}{c}0,566 \\
(0,891) \\
\end{array}$ & $\begin{array}{c}0,584 \\
(0,903) \\
\end{array}$ & $\begin{array}{c}0,388 \\
(0,631) \\
\end{array}$ \\
\hline \multicolumn{4}{|l|}{ Variáveis independentes } \\
\hline Presidência & $\begin{array}{l}-1,021 \\
(1,564) \\
\end{array}$ & $\begin{array}{l}-0,911 \\
(1,584) \\
\end{array}$ & Omitido \\
\hline Votação Presidente & $\begin{array}{c}0,0668^{* * *} \\
(0,0227)\end{array}$ & $\begin{array}{c}0,0635^{* * *} \\
(0,0234)\end{array}$ & - \\
\hline Votação Coligação Presidente & - & - & $\begin{array}{l}0,0305^{* *} \\
(0,0140)\end{array}$ \\
\hline Presidente Incumbente & $\begin{array}{c}0,481 \\
(1,594) \\
\end{array}$ & $\begin{array}{l}-1,939 \\
(4,688) \\
\end{array}$ & Omitido \\
\hline Votação Presidente Incumbente & - & $\begin{array}{c}0,0487 \\
(0,0888)\end{array}$ & Omitido \\
\hline Governo Estadual & $\begin{array}{c}1,696 \\
(1,379) \\
\end{array}$ & $\begin{array}{c}1,718 \\
(1,386) \\
\end{array}$ & Omitido \\
\hline Votação Governador & $\begin{array}{c}0,0948^{* * *} \\
(0,0320)\end{array}$ & $\begin{array}{c}0,0955^{* * *} \\
(0,0326)\end{array}$ & - \\
\hline Votação Coligação Governador & - & - & $\begin{array}{c}0,0176 \\
(0,0110) \\
\end{array}$ \\
\hline Governador Incumbente & $\begin{array}{c}1,478 \\
(1,373) \\
\end{array}$ & $\begin{array}{c}2,544 \\
(4,398) \\
\end{array}$ & Omitido \\
\hline Votação Governador Incumbente & - & $\begin{array}{l}-0,0235 \\
(0,0892) \\
\end{array}$ & Omitido \\
\hline Presidência e Governo Estadual & $\begin{array}{c}0,712 \\
(1,825) \\
\end{array}$ & $\begin{array}{c}0,475 \\
(1,890) \\
\end{array}$ & Omitido \\
\hline Votação Anterior & $\begin{array}{l}0,628^{* * *} \\
(0,0454)\end{array}$ & $\begin{array}{l}0,633^{* * *} \\
(0,0464)\end{array}$ & $\begin{array}{l}0,549^{* * *} \\
(0,0276)\end{array}$ \\
\hline Observações & 219 & 219 & 403 \\
\hline $\mathrm{R}^{2}$ ajustado & 0,655 & 0,653 & 0,529 \\
\hline
\end{tabular}

Fonte: Elaboração da autora a partir de dados do TSE (2011) e de Nicolau (2006).

Obs.: erro padrão entre parênteses. ${ }^{*} \tilde{\mathrm{n}}<0,01,{ }^{* *} \tilde{\mathrm{n}}<0,05,{ }^{* * *} \tilde{\mathrm{n}}<0,1$ 
contrados apontam que a ocupação de cargos majoritários não se revelou importante na definição da votação dos partidos para câmara baixa; partidos à frente do Executivo nacional ou de governos estaduais não impulsionaram seus partidários na corrida legislativa. $O$ fato de $o$ partido ter um presidente ou governador incumbente poderia ser um fator adicional de impulso à eleição para deputado federal, mas também aqui não encontramos correlações com significância estatística. $\mathrm{O}$ modelo 2, com o mesmo número de observações e $R^{2}$, ao introduzir a votação dos presidentes e governadores incumbentes, obteve resultados similares ao modelo 1 e não significância estatística para as variáveis de votação dos incumbentes. Nos dois modelos, o problema da não significância estatística nas variáveis de incumbentes pode ser decorrente de um número baixo de observações, dado que, para o período, somente houve duas possibilidades de reeleição para presidente e governador de estado. O mesmo deve ser o caso para os partidos que tiveram simultaneamente a Presidência e o Governo do estado em disputa.

Tais achados podem ainda estar relacionados a um fator já mencionado anteriormente neste artigo e não considerado dentre as variáveis independentes, a popularidade do presidente ou governador à época da eleição, como salientaram Pereira e Rennó (2007). A alternância de poder verificado na Presidência da República, e em muitos dos governos estaduais no período, aponta que, no processo eleitoral, nem sempre os que estiveram à frente dos cargos majoritários foram cabos eleitorais importantes para seus partidos, sendo exemplar a baixa popularidade de Fernando Henrique Cardoso ao final do seu segundo mandato.

Com isto, os resultados não corroboram a tese do poder dos governadores sobre a eleição para deputado federal no Brasil, conforme defendem Abrucio (1998) e Samuels (2003). O fato de controlar importantes recursos de poder não faz dos governadores as "locomotivas" das eleições parlamentares federais. E isto ocorre por diversos motivos, primeiro porque os recursos de poder dos governadores podem variar em função do contexto político e econômico de cada estado; segundo e mais importante, porque uma baixa popularidade do governante pode minimizar ou mesmo anular os efeitos destes recursos; e, ainda, porque a análise centrada no governador desconsidera a própria dinâmica da competição eleitoral, na qual importa a articulação de candidaturas majoritárias e proporcionais, bem como a força e o prestígio da oposição junto ao eleitorado. 
No que se refere aos coattails, verificamos nos dois modelos a presença de coattails presidenciais e governatoriais nas eleições legislativas, com alta significância estatística, ao nível de 1\%. Candidatos fortes a presidente ou a governador de estado potencializaram a votação do partido para deputado federal, sendo que este efeito foi maior para governadores (coattails governatoriais) que para presidentes (coattails presidenciais). Este resultado é similar ao verificado por Samuels (2003) para dois períodos democráticos brasileiros: 1945-1964 e 1989-1998.

O modelo 3, ao considerar todos os partidos que não tiveram candidatos próprios à Presidência ou aos governos dos estados entre $1994 \mathrm{e}$ 2010, mas que participaram de coligações para estes cargos, teve o número de observações elevado para 403 e uma queda no poder de predizer a votação para deputado federal, com um $\mathrm{R}^{2}$ de $53 \%$. Este modelo omite variáveis independentes utilizadas no primeiro modelo, o que é justificado pelo fato de que partidos sem candidatos próprios aos cargos executivos são aqueles que não estavam à frente da Presidência e dos governos estaduais, tampouco pleitearam a reeleição nestes cargos. Neste modelo, foram identificados coattails presidenciais, ou seja, as coligações eleitorais para presidente impactaram positivamente $o$ conjunto dos partidos aliados, com significância estatística ao nível de $5 \%$, e de forma bem menos expressiva do que quando o partido teve um candidato forte a presidente. $\mathrm{O}$ mesmo efeito não se verificou para as coligações governatoriais. Os dados indicam que a busca de votos para deputado federal nos distritos enfrenta contextos diversos de competição partidária estadual e federal, o que leva a estratégias distintas com respeito às candidaturas majoritárias nos dois níveis. Estes resultados parecem congruentes, não seria esperado algo expressivo no efeito de candidaturas presidenciais ou governatoriais sobre as eleições legislativas de outros partidos coligados, quando comparada a situação de ter candidatos próprios aos cargos executivos. Contudo, se um partido ter candidato forte a governador prevalece em termos de impulso ao voto legislativo, sem espaço para benefícios aos partidos coligados; inversamente, diante da impossibilidade de lançar um candidato forte à Presidência, alguma vantagem parece haver em "pegar carona" em outra candidatura.

Nos três modelos, obtivemos coeficientes expressivos e significância estatística no nível de 1\% para a variável independente "Votação Anterior", indicando a robustez dessa variável na explicação da votação 
dos deputados federais. Estas correlações indicam que os partidos políticos entram na competição política estadual para os cargos de deputado federal com um capital eleitoral que, de certa forma, independe do contexto das eleições majoritárias. Ainda, vale apontar que o capital dos partidos nas eleições para deputado federal é composto pelo capital de alguns indivíduos com alta performance eleitoral, os denominados "puxadores de voto". Este aspecto foge aos propósitos de trabalho, mas deve ser apresentado no intuito de evitar uma conclusão fácil sobre a força dos partidos nas eleições legislativas nacionais.

Em suma, se queremos saber qual será a votação de um partido político para deputado federal em determinada eleição, o melhor preditor é a votação que esse partido obteve na eleição anterior. Contudo, ter um candidato forte ao Governo federal ou, principalmente, ao Governo estadual se apresentou, dentre as variáveis, como a melhor forma de impulsionar a votação de um partido para a Câmara dos Deputados. E na falta de um cabeça de chapa para as eleições presidenciais, há ganhos em coligar-se a um partido forte para esta disputa. Estes resultados mostram que a dinâmica eleitoral brasileira não é tão volátil e que há certa regularidade presente, inclusive, nas votações para deputado federal. Ao menos isto é válido para o período mais recente, pós-1994, marcado por maior estabilidade econômica e política no país.

\section{CONSIDERAÇÕES FINAIS}

O artigo buscou analisar os efeitos majoritários, da ocupação e postulação dos cargos de presidente e governador de estado, sobre as eleições proporcionais para a Câmara dos Deputados brasileira. Os resultados encontrados não apontaram impactos da ocupação de cargos majoritários, seja presidente ou governador, nas votações dos partidos para deputado federal. Por outro lado, observa-se que partidos com candidatos fortes à Presidência ou aos governos estaduais impulsionaram suas votações para deputado federal, sendo os efeitos coattails governatoriais mais expressivos que os efeitos coattails presidenciais. No caso da presidência, observa-se ainda que partidos fortes nesta disputa impulsionaram a votação de partidos coligados para deputado federal. Verificamos também uma forte correlação entre a votação dos partidos na eleição para deputado federal e a votação recebida por esses mesmos partidos em eleição anterior. Como analisar tais achados à luz da literatura política sobre eleições e comportamento parlamentar, conforme autores citados no decorrer deste trabalho? 
Primeiramente, ao discriminar os efeitos majoritários de ocupantes e postulantes aos cargos de presidente e governador, é possível ter maior clareza sobre as relações causais e evitar certas confusões presentes na literatura que defende a tese do poder dos governadores na arena eleitoral e na política nacional. Assim, os resultados encontrados não respaldam a tese de poder dos governadores sobre as eleições para deputado federal. Os governadores, assim como os presidentes, não se mostraram como a locomotiva das eleições parlamentares. Contudo, os outros atores políticos se mostraram relevantes para as eleições legislativas, os candidatos a presidente e a governador de estado; estes últimos mais relevantes que os primeiros.

Os efeitos coattails governatoriais presentes e mais expressivos que os presidenciais apresentam uma faceta importante da dinâmica eleitoral brasileira que precisa ser melhor explorada em suas causas e consequências, algo para além dos objetivos deste artigo, mas que aponta uma agenda futura de pesquisa. Entre as causas, vale explorar por que candidatos a governador são importantes e, ainda, mais importantes que os candidatos a presidente, nas eleições de suas legendas para deputado federal. O que está por trás desta vinculação eleitoral: recursos de campanha, força de alguns partidos ou candidatos no plano estadual, associações feitas pelo eleitorado?

Conforme Ames (2003) e Carvalho (2003), um recorte municipal também pode ser informativo das eleições legislativas. Estudos destes autores apontaram padrões muito distintos de distribuição espacial dos votos para deputado federal nos estados, padrões que só poderiam ser melhor entendidos quando a referência fosse os municípios. Em uma pesquisa mais ampla, poderiam ser testados os efeitos da ocupação de prefeituras e de coattails prefeituriais sobre as eleições legislativas, mesmo com o descolamento temporal entre as eleições municipais e nacionais.

Em relação às consequências dos resultados encontrados, vale também reintroduzir o debate dos possíveis impactos da dinâmica eleitoral sobre o comportamento parlamentar, para além das votações nominais. Tendo como pressuposto que a arena eleitoral é limitada para definir o comportamento parlamentar e que outras variáveis de funcionamento interno do Legislativo e da relação Executivo e Legislativo nacionais devem ser consideradas, como afirmam diversos estudiosos do Legislativo brasileiro, destacando Figueiredo e Limongi (2001), ainda as- 
sim, resta a questão de como a dinâmica eleitoral pode interferir na dinâmica parlamentar. Com isto, o objetivo não é dizer que o resultado seja indisciplina partidária e falta de apoio às iniciativas legislativas do presidente, mas tão somente que as composições e barganhas políticas podem ser afetadas pela dinâmica eleitoral, com padrões distintos de cooperação e custos na relação Executivo e Legislativo.

Se estar à frente da Presidência ou de governos estaduais não significa, necessariamente, mais votos para os partidos na próxima disputa legislativa nacional e, ainda, se os partidos detêm algum capital eleitoral nos estados que se perpetua pelas eleições, isto pode significar certa independência na atuação de partidos e parlamentares em relação aos presidentes e governadores de estado? Mas o que dizer dos efeitos das eleições governatoriais sobre as eleições legislativas? Partidos e parlamentares podem atuar visando a construção de candidaturas fortes ao governo no plano estadual, em detrimento do plano federal? O caso do PMDB seria exemplar de uma estratégia que não prioriza candidatura própria à presidência, mas centra recursos na dinâmica estadual e na busca de recursos para atuar neste nível, inclusive por meio de participação na base aliada do governo federal?

A conclusão geral é que o federalismo é um componente importante para entender a composição do Legislativo nacional, mas são necessárias mais pesquisas para conhecimento da dinâmica eleitoral e de seus impactos nas relações Executivo e Legislativo no plano nacional.

(Recebido para publicação em fevereiro de 2011) (Reapresentado em julho de 2012) (Aprovado para publicação em fevereiro de 2013) 


\section{NOTAS}

1. O termo coattail se refere às abas traseiras de um fraque que, demasiadamente compridas, arrastam objetos ao se deslocar. A metáfora foi utilizada pela Ciência Política dos Estados Unidos para se referir ao "puxador de votos", ou seja, a capacidade que tem um candidato forte de arrastar votos para outros candidatos do seu partido. Por exemplo, um candidato à presidência forte pode impulsionar a votação do seu partido nas eleições legislativas.

2. Entre os modelos de Samuels (2003), um deles, cujo resultado foi a prevalência de efeitos coattails governatoriais sobre os presidenciais, apresenta um importante erro de especificação, conforme Brambor, Clark e Golder (2006). A deficiência está na omissão de termos constitutivos de variáveis de interação que compõem o modelo. Ao replicar o modelo com as devidas inclusões, os autores encontraram resultados opostos aos de Samuels: efeitos coattails presidenciais mais expressivos que efeitos coattails governatoriais.

3. Este modelo segue sugestão de parecerista do artigo, que considerou importante verificar o impacto da votação de presidentes ou governadores incumbentes sobre a votação dos partidos para deputado federal. Para obter as variáveis independentes de votação dos candidatos incumbentes (presidente ou governador), utilizamos interações entre as variáveis dicotômicas, ser presidente ou ser governador incumbente, e as variáveis de votação do presidente ou governador. 


\section{REFERÊNCIAS BIBLIOGRÁFICAS}

ABRUCIO, Fernando Luiz. (1998), Os Barões da Federação: Os Governadores e a Redemocratização Brasileira. São Paulo, Hucitec/USP.

AMES, Barry. (2003), Os Entraves da Democracia no Brasil. Rio de Janeiro, FGV Editora.

AMORIM NETO, Octavio. (2000), “Gabinetes Presidenciais, Ciclos Eleitorais e Disciplina Legislativa no Brasil". Dados, vol. 43, no 3, pp. 479-519.

eSANTOS, Fabiano. (2001), “A Conexão Presidencial: Facções Pró e Antigoverno e Disciplina Partidária no Brasil”. Dados, vol. 44, no 2, pp. 292-321.

. . (2003), “O Segredo Ineficiente Revisto: O que Propõem e o que Aprovam os Deputados Brasileiros". Dados, vol. 46, no 4, pp. 661-698.

BORN, Richard. (1984), "Reassessing the Decline of Presidential Coattails: U.S. House Elections from 1952-80". The Journal of Politics, vol. 46, no I, pp. 60-79.

BRAMBOR,Thomas, CLARK, Willian R. e GOLDER, Matt. (2006), “Understanding Interaction Models: Improving Empirical Analyses". Political Analysis, vol. 14, pp. 63-82.

CARVALHO, Nelson Rojas de. (2003), E no Início Eram as Bases: Geografia Política e Comportamento Legislativo no Brasil. Rio de Janeiro, Editora Revan.

CHEIBUB, José Antonio, FIGUEIREDO, Argelina e LIMONGI, Fernando. (2003), “Quem Manda em Quem na Esfera Federal?”. Insight/Inteligência, ano V, no 21, pp. 97-106.

COX, Gary W. e MCCUBBINS, Mathew D. (1993), The Legislative Leviathan: Party Government in the House. Berkeley, University of California Press.

DIAP (Departamento Intersindical de Assessoria Parlamentar). (2010), Eleições 2010. Disponível em: http://www.diap.org.br/index.php/eleicoes-2010/camara-dosdeputados/camara-renova-4425-novos-ficam-abaixo-da-media-historica. Acessado em: março de 2011.

FEREJOHN, John e CALVERT, Randall. (1984), “Presidential Coattails in Historical Perspective". American Journal of Political Science, vol. 28, no I, pp. 127-146.

FIGUEIREDO, Argelina C. e LIMONGI, Fernando. (2001), Executivo e Legislativo na Nova Ordem Constitucional (2a ed.). Rio de Janeiro, Editora FGV.

GARMAN, Christopher, HAGGARD, Stephan e WILLIS, Eliza. (2001), “Fiscal Decentralization: A Political Theory with Latin American Cases". World Politics, vol. 53, no 2, pp. 205-236.

LINZ, Juan. (1990), “The Perils of Presidentialism". Journal of Democracy, vol. 1, no 1, pp. 51-69.

MAINWARING, Scott P. (2001), Sistemas Partidários em Novas Democracias: O Caso do Brasil. Porto Alegre/Rio de Janeiro, Mercado Aberto/ FGV Editora.

NICOLAU, Jairo M. (org.). (2006), Dados Eleitorais do Brasil (1982-2006). Disponível em: http:/ / jaironicolau.iesp.uerj.br/banco2004.html. Acessado em: março de 2011.

PEREIRA, Carlos e MUELLER, Bernardo. (2001), “Comportamento Estratégico em Presidencialismo de Coalizão: As Relações entre o Executivo e Legislativo na Elaboração do Orçamento Brasileiro". Dados, vol. 45, no 2, pp. 265-301.

DADOS - Revista de Ciências Sociais, Rio de Janeiro, vol. 56, nำ 2, 2013 
PEREIRA, Carlos e RENNÓ, Lucio. (2007), “O que é que o Reeleito Tem? O Retorno: O Esboço de uma Teoria da Reeleição no Brasil". Revista de Economia Política. vol. 27, no 4, pp. 664-683.

SAMUELS, David J. (2003), Ambition, Federalism, and Legislative Politics in Brazil. Cambridge, Cambridge University Press.

e MAINWARING, Scott. (2004), “Strong Federalism, Constraints on the Central Government, and Economic Reform in Brazil", in E. Gibson (ed.), Federalism and Democracy in Latin America. Baltimore, The Johns Hopkins University Press.

SANTOS, Fabiano. (1997), "Patronagem e Poder de Agenda na Política Brasileira”. Dados, vol. 40, no 3, pp. 465-492.

. (1999), "Instituições Eleitorais e Desempenho do Presidencialismo no Brasil". Dados, vol. 42, no 1, pp.111-138.

SHUGART, Mathew e CAREY, John M. (1992), Presidents and Assemblies: Constitutional Design and Electoral Dynamics. Cambridge, Cambridge University Press.

TSE (TRIBUNAL SUPERIOR ELEITORAL). (2011), Eleições. Disponível em http:/ / www.tse.gov.br/internet/index.html. Acessado em 2007 e 2011. 


\section{ABSTRACT \\ Majority Influence in At-Large Elections: Presidential and Gubernatorial Effects on Elections to the Brazilian Chamber of Deputies (1994-2010)}

The article analyzes the impact of the election to (and occupation of) majority national and state executive positions (President and Governors) on the political parties' electoral performance in the elections to the lower house in Brazil during the recent democratic period (1994-2010). A database was built for the last five national and state elections and was used to conduct statistical regression analyses. According to the findings, the occupation of majority executive positions (President or Governors) had no effect on voting for National Deputies. However, having strong Presidential or Gubernatorial candidates bolstered the party's election results for National Deputy (the effect was greater for Governor than for President). The political parties also displayed electoral capital in the race for the national legislative branch, independently of majority influences.

Key words: legislative elections; Brazilian Federalism; Chamber of Deputies

\section{RÉSUMÉ}

Influence Majoritaire lors de Scrutins Proportionnels: Les Effets de Ceux des Gouverneurs des États du Brasil et de la Présidentielle sur les Élections de la Chambre des Députés (1994-2010)

Dans cet article, on examine l'impact de l'occupation et de l'élection à des postes majoritaires du pouvoir exécutif national et de chaque état, pour ceux de président et de gouverneurs d'état, sur les performances électorales des partis politiques à la chambre basse brésilienne dans la période démocratique récente (1994-2010). Pour entreprendre cet examen, on a construit une base de données concernant les cinq dernières élections à la présidence et aux états de la fédération et on les a soumises à des analyses de régression statistique. Les résultats montrent que l'occupation des postes majoritaires de président ou de gouverneur d'état, ne cause pas d'effets sur les votes pour l'élection des députés fédéraux. Mais, disposer de candidats forts à la présidence ou aux gouvernements d'état favorise les élections du parti pour le poste de député fédéral, l'effet étant plus important pour les gouverneurs que pour les présidents. Il s'est aussi avéré que les partis politiques bénéficient d'un capital électoral dans la lutte pour les postes du législatif national, capital qui n'est pas soumis aux influences majoritaires.

Mots-clés: élections législatives; fédéralisme brésilien; Chambre des Députés 